\title{
Biochemical and Immunologic Characterization of Serum Biotinidase in Partial Biotinidase Deficiency
}

\author{
P. SUZANNE HART, JEANNE HYMES, AND BARRY WOLF \\ Departments of Human Genetics [P.S.H., J.H., B.W.] and Pediatrics [B.W.], Medical College of Virginial \\ Virginia Commonwealth University, Richmond, Virginia 23298
}

\begin{abstract}
Newborn screening for biotinidase deficiency has identified children with profound biotinidase deficiency (less than $10 \%$ of mean normal activity) and about an equal number of children with partial biotinidase deficiency (10 to $30 \%$ of mean normal activity). Partial biotinidase deficiency was initially considered a variant without clinical consequences until one child, during an episode of gastroenteritis, developed symptoms of biotinidase deficiency that resolved with biotin therapy. Biochemical and immunologic characterization of biotinidase was performed in sera from 23 children with partial biotinidase deficiency from 19 families and 18 of their parents. As expected, all patients had cross-reacting material in their serum. Patients with partial biotinidase deficiency can be classified into six distinct biochemical phenotypes on the basis of the number of isoforms and the distribution frequency of the isoforms. Kinetic studies were performed on samples from 17 of the patients and were found to be normal in all cases. The patient with partial deficiency who became symptomatic has an isoform profile that is not different from 10 other asymptomatic, partially deficient children. The parents had normal isoform patterns. The isoform patterns observed in the patients with partial biotinidase deficiency were not different from those of the profoundly deficient patients who had cross-reacting material. (Pediatr Res 31: 261265,1992 )
\end{abstract}

\section{Abbreviations}

CRM, cross-reacting material

BPABA, N-biotinyl-p-aminobenzoate

Biotinidase (EC 3.5.1.12) is required for the normal recycling of biotin that has been incorporated into the four known human biotin-dependent carboxylases. A deficiency of biotinidase activity has been identified as the primary biochemical defect in most patients with autosomal recessively inherited disorder, late-onset multiple carboxylase deficiency (1). As a result of this deficiency, biotin cannot be liberated from endogenous or exogenous protein-bound states, resulting in a deficiency of biotin, which, in turn leads to secondary deficiencies of the carboxylases.

To date, 83 children with profound biotinidase deficiency $(<10 \%$ mean normal activity) have been ascertained clinically (2). The clinical features of the disorder include seizures, ataxia,

Received September 9, 1991; accepted November 11, 1991

Correspondence: Barry Wolf, M.D., Ph.D., Department of Human Genetics, Medical College of Virginia, P.O. Box 33, MCV Station, Richmond, VA 23298.

Supported by Grants DK 33022 and HD 23223 from the National Institutes of Health. P.S.H. is the recipient of a March of Dimes Predoctoral Fellowship (no. 18-87-09). hypotonia, hearing loss, skin rash, alopecia, and developmental delay (1). All children with biotinidase deficiency have improved after biotin treatment, and, if treatment is initiated early, it essentially reverses most of the symptoms and biochemical abnormalities (3). Because coma and death can result if the disorder is untreated, it is important that affected individuals be identified as early as possible and biotin therapy begun.

Newborn screening for biotinidase deficiency is currently conducted in many states and countries. Between January 1984 and December 1988, out of 4396834 infants screened for biotinidase deficiency in 12 countries, 72 infants were detected with the enzyme deficiency (4). Of these, 32 were profoundly deficient and 40 were partially deficient (10-30\% mean normal activity).

Before the implementation of newborn screening for biotinidase deficiency, partial biotinidase deficiency was unknown. Because all symptomatic children have had less than $10 \%$ mean normal activity, some parents of children with partial biotinidase deficiency have elected not to treat their children with biotin. One untreated patient, with approximately $30 \%$ of mean normal activity, developed a rash, hypotonia, and occipital hair loss at the age of $6 \mathrm{mo}$ after an episode of gastroenteritis (5). Biotin therapy was immediately initiated and the symptoms resolved.

We have shown that serum biotinidase exhibits extensive microheterogeneity on isoelectric focusing electrophoresis, primarily due to differences in the degree of sialyation of the protein (6). Using polycloncal antibodies to purified biotinidase, sera from patients with profound biotinidase deficiency were evaluated for the presence of CRM to the enzyme. Two large groups were found, those with CRM and those lacking CRM (7). The CRM-positive patients could be further classified on the basis of the number of isoforms and the distribution frequency of the isoforms. The isoform patterns of profoundly deficient children ascertained by newborn screening were not different from those of symptomatic children. We report the characterization of biotinidase in sera from 23 children with partial biotinidase deficiency and their parents.

\section{MATERIALS AND METHODS}

Serum samples. Sera were obtained from 23 individuals with partial biotinidase deficiency from 19 families. Sera were available from 18 parents of children with partial deficiency for immunologic characterization. Sera were available from 10 additional parents and 15 control individuals for kinetic studies. The biotinidase activities in the serum samples from individuals with partial deficiency ranged from 0.80 to $2.10 \mathrm{nmol} / \mathrm{min} / \mathrm{mL}$ (11.3-30\% mean normal activity). The activities of sera from the parents ranged from 1.42 to $5.70 \mathrm{nmol} / \mathrm{min} / \mathrm{mL}$. The procurement of these samples was approved by the Human Investigation Committee of the Medical College of Virginia.

Assay of biotinidase in serum. Biotinidase activity was determined using the colorimetric assay as described previously (1). 

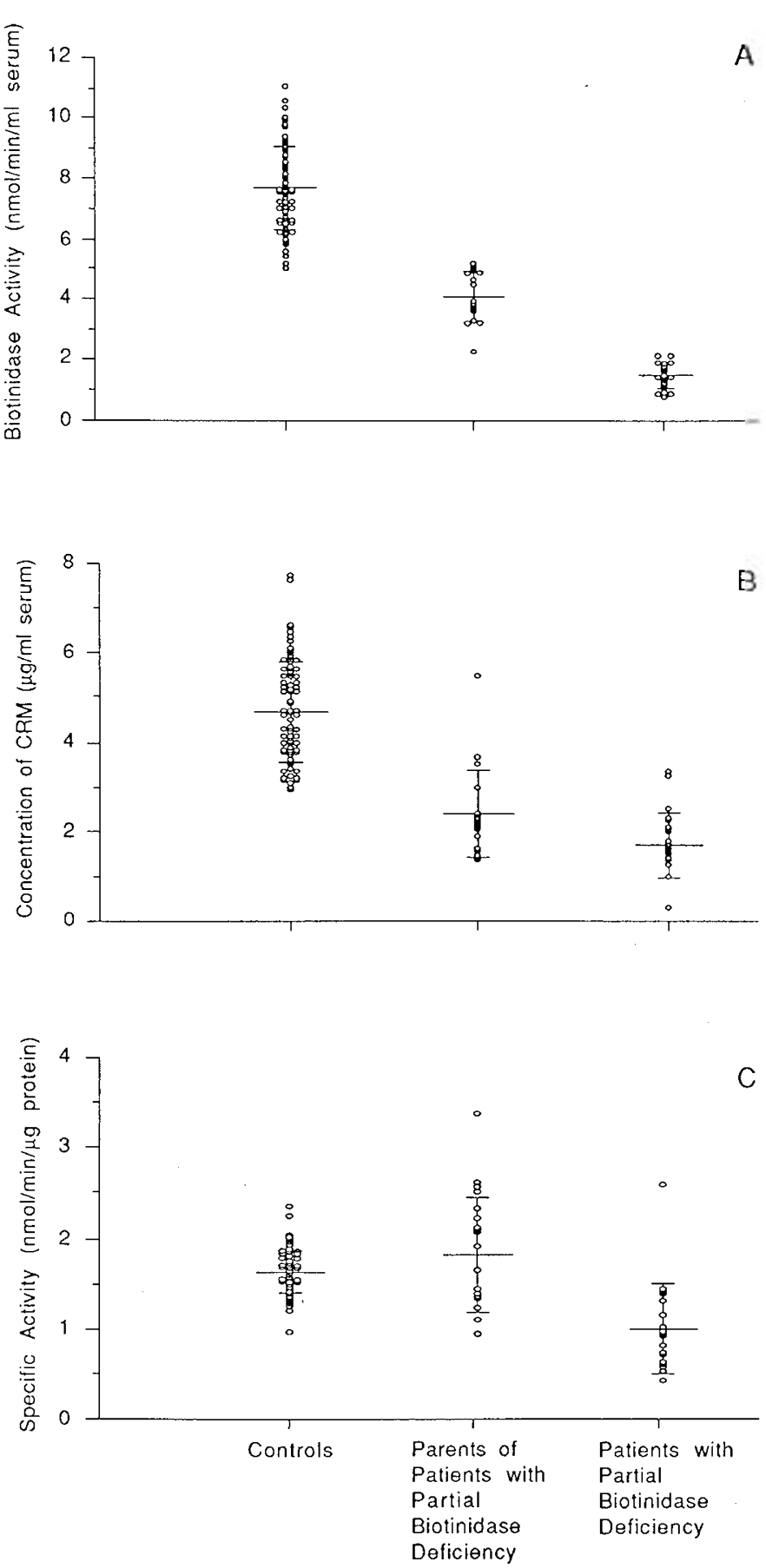

Fig. 1. Distribution of biotinidase activity, concentration of CRM, and $\mathrm{sp}$ act in children with partial biotinidase deficiency, their parents, and normal individuals. Bar indicates mean $\pm \mathrm{SD}$ for each group. $A$, Distribution of biotinidase activity in normal individuals (mean $=7.57$ $\pm 1.41 \mathrm{nmol} / \mathrm{min} / \mathrm{mL}$ serum, $n=100$ ), parents of children with partial deficiency (mean $=4.07 \pm 0.85, n=18$ ), and patients with partial biotinidase deficiency (mean $=1.47 \pm 0.41, n=23$ ). $B$, Distribution of the concentration of CRM in normal individuals (mean $=4.7 \pm 1.1 \mu \mathrm{g}$ / $\mathrm{mL}$ serum), parents of children with partial deficiency of serum biotinidase activity (mean $=2.4 \pm 1.0$ ), and patients with partial biotinidase deficiency $($ mean $=1.7 \pm 0.7)$. $C$, Distribution of the sp act of biotinidase in normal individuals (mean $=1.6 \pm 0.2 \mathrm{nmol} / \mathrm{min} / \mu \mathrm{g}$ protein), parents of children with partial deficiency (mean $=1.90 \pm 0.64$ ), and patients with partial biotinidase deficiency $($ mean $=0.96 \pm 0.46)$

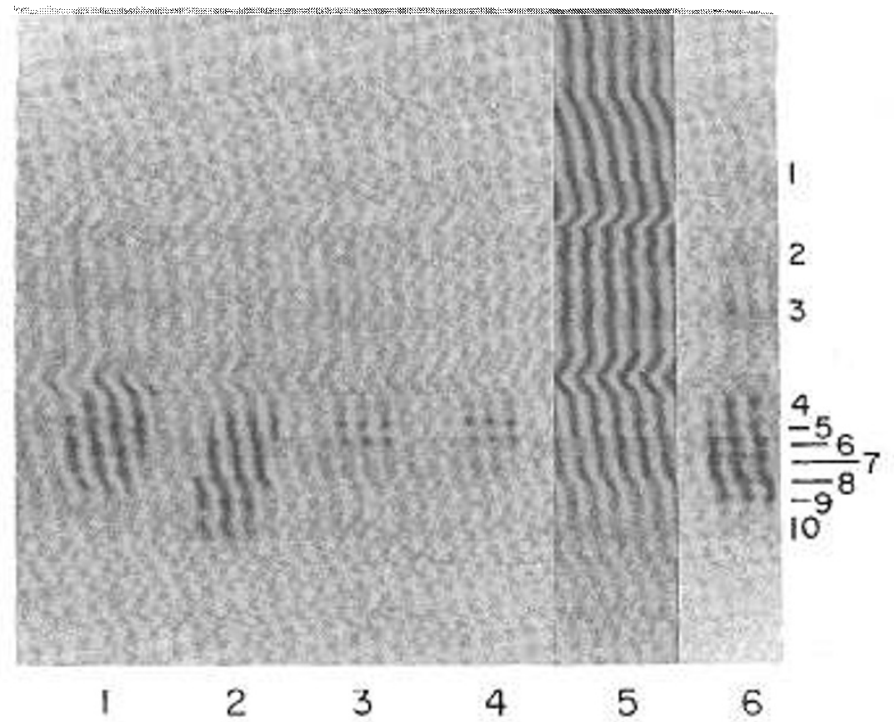

Fig. 2. Examples of the isoform patterns observed in sera from patients with partial biotinidase deficiency. Twenty $\mu \mathrm{L}$ of normal serum and $80 \mu \mathrm{L}$ of patient serum were focused on hybrid isoelectric focusing gels with a pH ranging from 4.1 to 4.4 . The cathode is located at the $t o p$ of the figure and the anode at the bottom. The pI of isoform 1 is approximately 4.31 . The pI of isoforms $4-10$ are clustered between 4.20 and 4.25. Lanes 1 and 2 are from patients with normal isoform patterns. Lane 1 is an example of a nine-isoform pattern and lane 2 is an example of a ten-isoform pattern. Lanes 3 and 4 are from patients whose sera lack isoform 9. The individual in lane 5 is missing isoforms 8 and 9. Lane 6 is an individual with normal biotinidase activity. The isoforms are designated by number.

Isoelectric focusing gel electrophoresis of biotinidase. Isoelectric focusing was performed as described previously (7). Briefly, $7.5 \%$ polyacrylamide hybrid isoelectric focusing gels with a $\mathrm{pH}$ gradient of 4.1-4.4 were cast with the addition of $2.5 \%$ carrier ampholines ( $\mathrm{pH} 2.5-4.5$ ) to the acidic and basic solutions. Eighty $\mu \mathrm{L}$ of patient serum and $40 \mu \mathrm{L}$ of parent serum were applied to the surface of the gel using filter paper.

Immunoblot analysis and quantitation of CRM. Immunoblot analysis and quantitation of CRM were performed as described previously (7). The isoform patterns of all patients with partial biotinidase deficiency and their parents were determined using 4-chloro-1-naphthol as the detection reagent. The amount of CRM per sample was determined by comparison with a standard sample focused on each gel as described previously (7).

Enzyme kinetic studies. The $\mathrm{Km}$ of $\mathrm{BPABA}$ and $\mathrm{V}_{\max }$ for biotinidase were determined using a modified microtiter colorimetric assay for biotinidase activity (7).

Statistical analysis. Statistical analysis was performed by the software package Statistical Analysis System (SAS) as described (7).

\section{RESULTS}

Characterization of Biotinidase in Sera from Patients with Partial Biotinidase Deficiency. Isoform patterns. Analysis of sera from 23 patients with partial biotinidase deficiency (mean biotinidase activity $=1.47 \pm 0.40 \mathrm{nmol} / \mathrm{min} / \mathrm{mL} ;$ Fig. $1 A$ ) revealed that all patients were CRM-positive. The isoform patterns varied from the same as those of normal individuals $(n=10)$ to those in which one or more of the specific isoforms is missing $(n=13)$ (Fig. 2). Of the 10 patients with normal isoform patterns, four had nine isoforms and six had 10 isoforms. Except for one patient who was missing isoforms 7,8 , and 9 and one patient who was missing isoforms 8 and 9 , all other patients with partial biotinidase deficiency who were missing isoforms lacked only isoform 9 (Table 1). All isoform patterns were observed both in 
Table 1. CRM status, mean biotinidase activity, mean concentration of CRM, mean sp act, and distribution frequency of isoforms of biotinidase in sera from patients with partial biotinidase deficiency

\begin{tabular}{|c|c|c|c|c|c|c|c|c|c|c|c|c|c|c|}
\hline \multirow[b]{2}{*}{ Patient } & \multirow{2}{*}{$\begin{array}{c}\text { Isoforms } \\
\text { missing }\end{array}$} & \multirow{2}{*}{$\begin{array}{c}\text { Activity } \\
(\mathrm{nmol} / \mathrm{min} / \mathrm{mL})\end{array}$} & \multirow{2}{*}{$\begin{array}{c}\text { Concentration } \\
\text { of CRM } \\
(\mu \mathrm{g} / \mathrm{mL})\end{array}$} & \multirow{2}{*}{$\begin{array}{c}\mathrm{Sp} \text { act } \\
(\mathrm{nmol} / \mathrm{min} / \mu \mathrm{g})\end{array}$} & \multicolumn{10}{|c|}{$\begin{array}{l}\text { Distributions of isoforms } \\
\text { (\% of total) }\end{array}$} \\
\hline & & & & & 1 & 2 & 3 & 4 & 5 & 6 & 7 & 8 & 9 & 10 \\
\hline $\begin{array}{l}\text { Normals } \\
\text { (nine isoforms) }\end{array}$ & & & & & 2.8 & 4.1 & 4.4 & 9.3 & 16.0 & 20.0 & 19.2 & 17.6 & 6.1 & \\
\hline $\begin{array}{l}\text { Normals } \\
\text { (10 isoforms) }\end{array}$ & & & & & 2.5 & 5.8 & 6.1 & 10.6 & 12.1 & 17.8 & 19.3 & 17.6 & 7.4 & 2.4 \\
\hline PJ & & 1.81 & 1.2 & 1.45 & 1.4 & 1.8 & 1.9 & 2.1 & 13.6 & 20.8 & 23.8 & 19.6 & 10.1 & 5.2 \\
\hline YO & & 1.40 & 3.3 & 0.43 & 2.4 & 4.8 & 8.1 & 8.8 & 21.4 & 14.1 & 19.1 & 11.0 & 4.3 & 6.0 \\
\hline $\mathrm{SH}$ & & 1.40 & 2.3 & 0.61 & 0.5 & 1.1 & 2.3 & 16.1 & 35.8 & 28.0 & 11.4 & 2.8 & 1.6 & 0.4 \\
\hline LM & & 1.66 & 1.3 & 1.31 & 3.1 & 4.1 & 4.2 & 4.7 & 18.1 & 19.7 & 18.5 & 17.9 & 5.5 & 4.1 \\
\hline RA & & 0.95 & 1.8 & 0.53 & 5.0 & 6.3 & 3.6 & 7.7 & 12.0 & 31.6 & 20.4 & 9.5 & 1.8 & 2.0 \\
\hline $\mathrm{JL}$ & & 1.74 & 1.3 & 1.38 & 2.1 & 4.0 & 4.2 & 7.5 & 12.2 & 23.6 & 22.0 & 17.2 & 4.3 & 2.8 \\
\hline $\mathrm{KB}$ & & 1.12 & 2.1 & 0.53 & 3.8 & 5.7 & 6.8 & 8.1 & 17.7 & 31.0 & 15.5 & 8.0 & 3.5 & \\
\hline PR & & 0.80 & 0.3 & 2.58 & 4.7 & 9.5 & 5.7 & 7.6 & 12.0 & 26.6 & 18.3 & 12.2 & 3.3 & \\
\hline DH & & 1.20 & 1.3 & 0.94 & 4.5 & 8.2 & 5.9 & 7.9 & 10.0 & 21.9 & 25.6 & 9.7 & 6.2 & \\
\hline JP & & 1.80 & 2.5 & 0.72 & 4.0 & 5.2 & 3.1 & 18.3 & 21.3 & 18.4 & 16.1 & 9.6 & 4.0 & \\
\hline JA & 9 & 1.25 & 2.0 & 0.62 & 2.3 & 6.7 & 6.0 & 14.1 & 18.8 & 18.4 & 15.1 & 18.6 & & \\
\hline JD & 9 & 1.41 & 1.7 & 0.82 & 1.8 & 3.9 & 4.5 & 21.5 & 36.4 & 15.5 & 10.9 & 5.5 & & \\
\hline $\mathrm{MK}^{*}$ & 9 & 2.10 & 1.5 & 1.40 & 3.2 & 6.8 & 2.4 & 6.6 & 40.0 & 24.6 & 8.3 & 8.0 & & \\
\hline TK & 9 & 1.90 & 2.0 & 0.95 & 3.3 & 4.6 & 2.0 & 5.5 & 27.0 & 33.4 & 17.3 & 6.9 & & \\
\hline AR & 9 & 2.10 & 2.3 & 0.93 & 1.8 & 3.4 & 5.9 & 7.9 & 13.9 & 31.9 & 24.3 & 10.7 & & \\
\hline $\mathrm{HF}$ & 9 & 1.90 & 3.3 & 0.57 & 4.5 & 4.5 & 2.0 & 18.2 & 25.4 & 21.5 & 16.6 & 7.3 & & \\
\hline PW & 9 & 1.90 & 1.6 & 1.16 & 1.6 & 2.6 & 3.6 & 16.6 & 25.4 & 23.8 & 19.8 & 6.6 & & \\
\hline $\mathrm{AW}$ & 9 & 1.30 & 1.4 & 0.94 & 5.5 & 4.4 & 6.2 & 17.0 & 23.8 & 22.8 & 15.2 & 5.2 & & \\
\hline KW & 9 & 1.70 & 1.7 & 1.01 & 7.5 & 3.7 & 8.0 & 16.0 & 23.9 & 14.8 & 18.6 & 7.4 & & \\
\hline PR & 9 & 0.90 & 1.0 & 0.91 & 0.5 & 1.9 & 3.7 & 13.2 & 26.4 & 18.3 & 19.0 & 16.9 & & \\
\hline BR & 9 & 0.90 & 1.6 & 0.58 & 0.5 & 2.0 & 3.7 & 11.3 & 23.9 & 21.2 & 17.9 & 19.4 & & \\
\hline NP & 8,9 & 1.50 & 1.5 & 0.97 & 7.5 & 6.5 & 6.4 & 12.7 & 28.2 & 31.4 & 7.3 & & & \\
\hline CW & $7-9$ & 0.97 & 1.4 & 0.69 & 3.2 & 6.3 & 3.6 & 18.9 & 27.6 & 40.3 & & & & \\
\hline
\end{tabular}

* Child who became symptomatic after metabolic compromise.

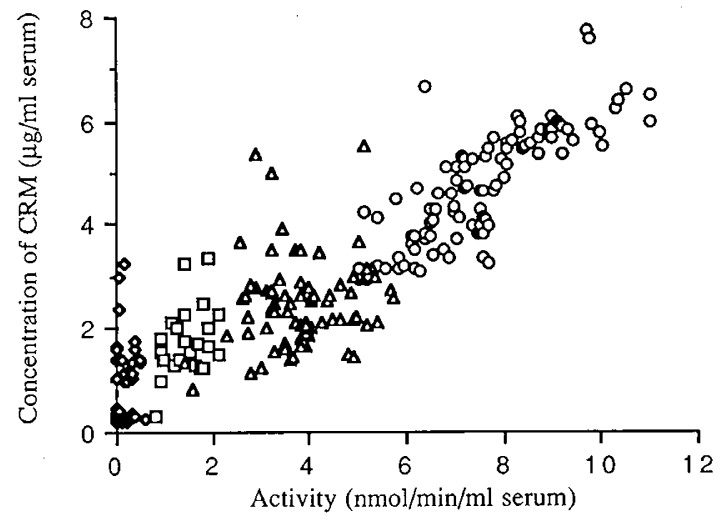

Fig. 3. The concentration of CRM in sera from patients with profound biotinidase deficiency $(\diamond)$, patients with partial deficiency $(\square)$, parents of children with profound and partial biotinidase deficiency $(\triangle)$, and individuals with normal biotinidase activity $(O)$ as a function of their serum biotinidase activity. Data from patients with profound biotinidase deficiency, their parents, and normal individuals were taken from reference 7 .

patients with profound deficiency and in those with partial deficiency except the pattern lacking isoforms $6-9$, which was only observed in one patient with profound deficiency (7).

Sera from three siblings of children with partial biotinidase deficiency were available for study. As was found in siblings with profound biotinidase deficiency, siblings with partial biotinidase deficiency had the same isoform pattern as the proband. One untreated child (MK) with an activity of $2.1 \mathrm{nmol} / \mathrm{min} / \mathrm{mL}$ became symptomatic after metabolic compromise (5). Analysis of this patient's isoform pattern revealed that he was missing isoform 9, as was his older asymptomatic brother (activity of 1.9 $\mathrm{nmol} / \mathrm{min} / \mathrm{mL}$ ). In addition, eight other asymptomatic patients had this same pattern.

CRM and sp act of biotinidase in sera from patients with partial biotinidase deficiency. The amount of CRM was determined in the serum from each patient with partial biotinidase deficiency as previously described (7). The results of this analysis are shown in Table 1 . The mean concentration of CRM was 1.8 $\pm 0.7 \mu \mathrm{g} / \mathrm{mL}$ (Fig. $1 B$ ). Patients with missing isoforms do not necessarily have concentrations of CRM that are less than those of patients with a normal number of isoforms. Two patients (YO and HF) had normal quantities of CRM. The amount of CRM varied between that found in samples from patients with profound biotinidase deficiency and that in samples from normal individuals (Fig. 3).

The mean sp act for patients with partial biotinidase deficiency was $1.0 \pm 0.4 \mathrm{nmol} / \mathrm{min} / \mu \mathrm{g}$ (Fig. $1 C$ ). Three patients (PJ, JL, and $\mathrm{MK}$ ) had sp act comparable to those found in normal individuals. The asymptomatic sibling of $\mathrm{MK}$, TK, had a sp act of $1.0 \mathrm{nmol} / \mathrm{min} / \mu \mathrm{g}$, which was lower than that of $\mathrm{MK}$. One patient (PR) had a sp act of $2.6 \mathrm{nmol} / \mathrm{min} / \mu \mathrm{g}$. The sp act of the patients with partial deficiency were generally higher than those of CRM-positive, profoundly deficient patients, reflecting both the higher biotinidase activities and higher amounts of CRM. The mean activities $(p<0.001)$, mean amounts of CRM $(p<$ $0.001)$, and mean sp ac $(p<0.001)$ differed significantly between patients with partial deficiency and CRM-positive patients with profound deficiency. The mean activities $(p<0.001)$, mean amounts of CRM $(p<0.001)$, and mean sp act $(p<0.001)$ also differed significantly between patients with partial deficiency and normal individuals.

As reported for patients with profound biotinidase deficiency, differences in the distribution frequencies of the isoforms were noted (Table 1). Generally, the distribution frequencies of patients with partial biotinidase deficiency with a normal number 
Table 2. $K_{m}$ of BPABA for biotinidase and $V_{\max }$ in sera from patients with partial biotinidase deficiency and their parents

\begin{tabular}{|c|c|c|}
\hline Serum source & $\mathrm{Km}(\mu \mathrm{M})$ & $\begin{array}{c}\mathrm{V}_{\max } \\
(\mathrm{nmol} / \mathrm{min} / \mathrm{mL})\end{array}$ \\
\hline \multicolumn{3}{|l|}{ Family 1} \\
\hline Proband (YO) & 21.5 & 0.7 \\
\hline Mother & 20.5 & 5.2 \\
\hline Father & 18.1 & 2.6 \\
\hline \multicolumn{3}{|l|}{ Family 2} \\
\hline Proband (MK) & 4.0 & 1.1 \\
\hline Affected sibling & 8.3 & 1.2 \\
\hline Mother & 8.8 & 2.5 \\
\hline Father & 16.1 & 4.8 \\
\hline \multicolumn{3}{|l|}{ Family 3} \\
\hline Proband (JL) & 6.0 & 0.7 \\
\hline Mother & 9.7 & 2.7 \\
\hline \multicolumn{3}{|l|}{ Family 4} \\
\hline Proband (JA) & 3.2 & 1.2 \\
\hline \multicolumn{3}{|l|}{ Family 5} \\
\hline Proband (PW) & 12.9 & 1.6 \\
\hline Mother & 17.5 & 2.1 \\
\hline Father & 20.0 & 3.1 \\
\hline \multicolumn{3}{|l|}{ Family 6} \\
\hline Proband (RA) & 7.2 & 1.5 \\
\hline Mother & 5.3 & 3.4 \\
\hline Father & 4.9 & 2.8 \\
\hline \multicolumn{3}{|l|}{ Family 7} \\
\hline Proband (JP) & 3.0 & 0.9 \\
\hline Mother & 5.4 & 2.7 \\
\hline Father & 6.3 & 3.2 \\
\hline \multicolumn{3}{|l|}{ Family 8} \\
\hline Proband (AR) & 10.6 & 1.2 \\
\hline Mother & 8.3 & 2.4 \\
\hline \multicolumn{3}{|l|}{ Family 9} \\
\hline Proband (NP) & 6.7 & 1.1 \\
\hline Mother & 9.1 & 3.0 \\
\hline Father & 5.7 & 2.9 \\
\hline \multicolumn{3}{|l|}{ Family 10} \\
\hline Proband (SH) & 5.2 & 1.0 \\
\hline Mother & 3.4 & 0.6 \\
\hline Father & 9.5 & 3.1 \\
\hline \multicolumn{3}{|l|}{ Family 11} \\
\hline Proband (DH) & 14.0 & 1.4 \\
\hline Mother & 5.1 & 2.0 \\
\hline Father & 10.9 & 2.2 \\
\hline \multicolumn{3}{|l|}{ Family 12} \\
\hline Proband (RB) & 3.6 & 0.6 \\
\hline Mother & 4.7 & 0.4 \\
\hline Father & 24.5 & 10.2 \\
\hline \multicolumn{3}{|l|}{ Family 13} \\
\hline Proband $(\mathrm{KW})$ & 10.4 & 0.5 \\
\hline Affected sibling & 7.8 & 0.5 \\
\hline Mother & 9.2 & 1.4 \\
\hline Father & 9.3 & 1.9 \\
\hline
\end{tabular}

of isoforms were more similar to those of normal individuals than to those of patients with profound deficiency. The distribution frequencies were again similar among siblings (MK and TK; AW and KW; PR and BR).

Kinetic studies of biotinidase. Kinetic parameters of biotinidase in serum of patients with partial biotinidase deficiency were compared with those of normal individuals. Because of the limited availability of sera from patients with biotinidase deficiency, we performed kinetic studies using the microtiter method for assaying biotinidase activity.

Enzyme kinetic studies were performed in sera from 15 individuals with normal biotinidase activity (mean activity $=7.67 \pm$ $1.16 \mathrm{nmol} / \mathrm{min} / \mathrm{mL}$ ). Using the microtiter method, the mean apparent $\mathrm{Km}$ of $\mathrm{BPABA}$ for biotinidase is $12.8 \pm 4.3 \mu \mathrm{M}$, which
Table 3. Enumeration of biochemical phenotypes of biotinidase resulting in partial enzyme deficiency based on results of this study

\begin{tabular}{cccl}
\hline $\begin{array}{c}\text { Degree of enzyme } \\
\text { deficiency }\end{array}$ & $\begin{array}{c}\text { CRM } \\
\text { status }\end{array}$ & $\begin{array}{c}\text { Isoforms } \\
\text { missing }\end{array}$ & $\begin{array}{c}\text { Isoform } \\
\text { distribution } \\
\text { frequency }\end{array}$ \\
\hline Partial $(n=5)$ & + & None & Normal \\
Partial $(n=5)$ & + & None & Abnormal \\
Partial $(n=4)$ & + & 9 & Similar* \\
Partial $(n=7)$ & + & 9 & Dissimilar $\dagger$ \\
Partial $(n=1)$ & + & 8,9 & \\
Partial $(n=1)$ & + & $7-9$ & \\
\hline
\end{tabular}

* Similar to other patients with same isoform pattern.

$\dagger$ Dissimilar to other patients with same isoform pattern.

is in agreement with previously published values $(1,8,9)$. The mean $\mathrm{V}_{\max }$ was $6.6 \pm 1.5 \mathrm{nmol} / \mathrm{min} / \mathrm{mL}$, which is consistent with previously reported results (1). Thus, it appears that this a valid method for determining the kinetic properties of the enzyme and can be used to study biotinidase from deficient patients.

Kinetic studies were performed on 15 patients with partial biotinidase deficiency (mean biotinidase activity $=1.61 \pm 0.36$ $\mathrm{nmol} / \mathrm{min} / \mathrm{mL}$ ) from 13 families and 22 of their parents. As shown in Table 2, none of the patients with partial enzyme deficiency were found to have an abnormally high $\mathrm{Km}$ for BPABA. The mean apparent $\mathrm{Km}$ and $\mathrm{V}_{\max }$ of BPABA for the patients' enzyme was $7.9 \pm 4.7 \mu \mathrm{M}$ and $1.0 \pm 0.3 \mathrm{nmol} / \mathrm{min} /$ $\mathrm{mL}$, respectively. The mean apparent $\mathrm{Km}$ and $\mathrm{V}_{\max }$ of BPABA for the parents' enzyme were $10.2 \pm 5.8 \mu \mathrm{M}$ and $2.6 \pm 1.1 \mathrm{nmol} /$ $\mathrm{min} / \mathrm{mL}$, respectively. The $\mathrm{Km}$ values were within the normal range.

Characterization of Biotinidase in Sera from Parents of Children with Biotinidase Deficiency. Isoform patterns, CRM, and sp act. The mean biotinidase activity in sera from parents of children with partial biotinidase deficiency was $4.07 \pm 0.85 \mathrm{nmol} /$ $\mathrm{min} / \mathrm{mL}$ (Fig. $1 A$ ). All parents of patients with partial biotinidase were found to have normal isoform patterns. Ten $(56 \%)$ of the parents had isoform 9 , seven $(39 \%)$ had isoform 10 , and one $(5 \%)$ had isoform 11 , which is in agreement $\left(\chi^{2}=3.57,0.25>\right.$ $p>0.10$ ) with the distribution of the isoforms in our control population ( $69 \%$ with isoform $9,21 \%$ with isoform 10 , and $10 \%$ with isoform 11) (7).

The quantity of CRM in samples from parents of children with partial biotinidase deficiency was generally lower than that found in individuals with normal biotinidase activity, with a mean of $2.4 \pm 1.0 \mu \mathrm{g} / \mathrm{mL}$ (Fig. $1 B$ ). The mean CRM in these parents was similar to that of parents of children with profound biotinidase deficiency (7). The mean sp act was $1.9 \pm 0.6 \mathrm{nmol} /$ $\mathrm{min} / \mu \mathrm{g}$ biotinidase protein (Fig. $1 C$ ), which is comparable to the mean sp act observed in normal individuals and parents of children with profound biotinidase deficiency. Thus, the parents of profoundly deficient children do not appear to be different in terms of mean activity $(p=0.19)$, mean concentration of CRM $(p=0.20)$, or sp act $(p=0.09)$ from parents of patients with partial deficiency.

Comparison of CRM of Biotinidase in Sera of Children with Biotinidase Deficiency, Their Parents, and Normal Individuals. The amount of CRM as a function of activity for profoundly and partially deficient patients, their parents, and normal individuals is shown in Figure 3 . Generally, the biotinidase activity is proportional to the concentration of CRM.

\section{DISCUSSION}

Newborn screening has revealed patients with partial deficiency of biotinidase, all of whom have sera that contains CRM to biotinidase. Of 15 patients with partial biotinidase deficiency, none were found to have an increased $\mathrm{Km}$ of BPABA for 
biotinidase. The finding of two patients with partial deficiency of biotinidase who have normal sp act is interesting. Although most patients with biotinidase deficiency, including these two, probably have a structural mutation, it is also possible that those individuals with partial deficiency and normal sp act may have a regulatory mutation. Thus, their biotinidase would have normal catalytic properties, but would possibly be synthesized in lesser quantities. They may have catalytically active enzyme that is rapidly degraded. Alternatively, these patients may also have normal amounts of catalytically active enzyme in their tissues, but be unable to secrete it into their serum. These studies were performed using an artificial substrate of biocytin. It is possible that differences in kinetics may be apparent when the natural substrate is used.

The patient who became symptomatic was found to be missing isoform 9. This same isoform pattern was found in 10 other asymptomatic patients, including the patient's brother. Because some of these children are being treated with biotin and those that are not may be too young, it is not known if this particular isoform pattern predisposes a patient with partial deficiency to become symptomatic.

As in patients with profound biotinidase deficiency, no abnormal electrophoretic variants were found. This suggests that if any of these patients have structural gene mutations, these mutations do not result in alterations in the protein that affects its electrophoretic mobility.

We have previously described nine different biochemical phenotypes that are associated with a profound deficiency of biotinidase activity (7). We now present six different biochemical phenotypes that are associated with a partial deficiency of biotinidase activity (Table 3). Thus, there may be as many as 15 different biochemical phenotypes associated with biotinidase deficiency. Other than the amount of residual activity in profoundly and partially deficient patients, there is overlap in the biochemical phenotypes. The identification of differences among patients with biotinidase deficiency on the basis of their isoform patterns may be useful in selecting which patients are likely to have different gene defects once the gene for biotinidase has been characterized.

There were no significant differences between mean activities, mean concentrations of CRM, or mean sp act of parents of children with profound deficiency compared to those with partial deficiency. Therefore, at this time, it is not possible to distinguish between heterozygotes for profound biotinidase deficiency and those for partial deficiency, unless they have an affected child.

Two patients were found to have normal concentrations of CRM. Sera was available from parents of one of these children (YO). Based on the sp act of biotinidase in sera from this child's parents, it is consistent that the parents have an allele that encodes a biotinidase molecule with low enzyme activity but that has normal immunoreactivity.

In conclusion, evidence now exists that there are six biochemical phenotypes associated with partial biotinidase deficiency based on the presence or absence of CRM, the number of isoforms, and the distribution frequency of the isoforms. The isoform patterns of partially deficient children are not different from CRM-positive children with profound biotinidase deficiency. Because one untreated patient with partial biotinidase deficiency developed symptoms of the disorder after metabolic compromise, it remains to be determined if it is beneficial to treat all patients with partial biotinidase deficiency with biotin.

Acknowledgments. The authors thank Drs. R. Allen, J. Ashbaugh, M. Blitzer, R. Laframboise, M. Lawler, M. Lohff, T. Mueller, K. Sasser, M. Schmidt, A. Slonim, S. Synderman, C. Strom, Werner, and L. Wong for providing us with patient samples.

\section{REFERENCES}

1. Wolf B, Grier RE, Allen RJ, Goodman I, Kien CL 1983 Biotinidase deficiency: the enzymatic defect in late-onset multiple carboxylase deficiency. Clin Chim Acta 131:273-281

2. Wolf B, Heard GS 1991 Biotinidase deficiency. In: Barness LA, DeVivo DC, Morrow III G, Oski FA, Rudolph AM (eds) Advances in Pediatrics. Year Book Medical Publishers, New York, pp 1-21

3. Wolf B, Grier RE, Secor McVoy JR, Heard GS 1985 Biotinidase deficiency: a novel vitamin recycling defect. J Inherited Metab Dis [Suppl] 1:53-58

4. Wolf B, Heard GS 1990 Screening for biotinidase deficiency in newborns: worldwide experience. Pediatrics 85:512-517

5. Secor McVoy JR, Levy HL, Lawler M, Schmidt MA, Hart PS, Dove Pettit D, Blitzer MG, Wolf B 1990 Partial biotinidase deficiency: clinical and biochemical features. J Pediatr 116:78-83

6. Hart PS, Hymes J, Wolf B 1991 Isoforms of human serum biotinidase. Clin Chim Acta 197:257-264

7. Hart PS, Hymes J, Wolf B 1991 Biochemical and immunological characterization of serum biotinidase in profound biotinidase deficiency. Am J Hum Genet (in press)

8. Chauhan J, Dakshinamurti K 1986 Purification and characterization of human serum biotinidase. J Biol Chem 261:4268-4275

9. Craft DV, Goss NH, Chandramouli N, Wood HG 1985 Purification of biotinidase from human plasma and its activity on biotinyl peptides. Biochemistry 24:2471-2476 